\title{
Smart Cutting Tools and Smart Machining: Development Approaches, and Their Implementation and Application Perspectives
}

\author{
Kai Cheng ${ }^{1}$ Zhi-Chao Niu ${ }^{1} \cdot$ Robin C. Wang ${ }^{1} \cdot$ Richard Rakowski $^{1}$ • \\ Richard Bateman ${ }^{1}$
}

Received: 19 December 2016/Revised: 8 May 2017/Accepted: 24 July 2017/Published online: 11 August 2017

(c) The Author(s) 2017. This article is an open access publication

\begin{abstract}
Smart machining has tremendous potential and is becoming one of new generation high value precision manufacturing technologies in line with the advance of Industry 4.0 concepts. This paper presents some innovative design concepts and, in particular, the development of four types of smart cutting tools, including a force-based smart cutting tool, a temperature-based internally-cooled cutting tool, a fast tool servo (FTS) and smart collets for ultraprecision and micro manufacturing purposes. Implementation and application perspectives of these smart cutting tools are explored and discussed particularly for smart machining against a number of industrial application requirements. They are contamination-free machining, machining of tool-wear-prone Si-based infra-red devices and medical applications, high speed micro milling and micro drilling, etc. Furthermore, implementation techniques are presented focusing on: (a) plug-and-produce design principle and the associated smart control algorithms, (b) piezoelectric film and surface acoustic wave transducers to measure cutting forces in process, (c) critical cutting temperature control in real-time machining, (d) inprocess calibration through machining trials, (e) FE-based design and analysis of smart cutting tools, and (f) application exemplars on adaptive smart machining.
\end{abstract}

Supported by the UK Technology Strategy Board (TSB) and Innovate UK (SEEM Project, Contract No.: BD266E; KTP Project, Contract No.: 9277).

Kai Cheng

kai.cheng@brunel.ac.uk

1 College of Engineering, Design and Physical Sciences, Brunel University London, Uxbridge UB8 3PH, UK
Keywords Smart cutting tool $\cdot$ Smart machining $\cdot$ Fast tool servo (FTS) · Precision machining · Micro manufacturing . Smart tooling

\section{Introduction}

Smart tooling and smart machining have tremendous potential and are drawing attention as one of next generation precision machining technologies particularly in the Industry 4.0 context [1-5]. In modern advanced manufacturing, it is becoming an essential trend for machining components with an ever increasing dimensional/form accuracy and finer surface roughness, even surface functionality requirement. In high precision machining, however, to position the cutting tool with such high accuracy and repeatability is the key and this is normally undertaken in a "passive" manner, i.e., the tool's position relying on the slideways' positioning accuracy but without measuring the tool cutting behaviour and process conditions. Furthermore, for many high value precision machining processes, it is important to use smart cutting tools to carry out the processes in a 'proactive' manner, in order to cope with machining dynamics, process variations and complexity. For instance, ultra-precision and micro machining, with the surface roughness normally at the nanometric scale and features/patterns at the micrometer level, is increasingly and continuously demanded particularly for high precision components and products with improved functionality and performance. The smart precision and micro manufacturing in a 'proactive' manner will be the way forward [6].

Aiming at high quality surfaces and dimensional/form accuracy, some monitoring methods have been proposed to 
monitor cutting forces with high precision and the process conditions. The variations of the cutting forces are most likely related to the tool wear or other process conditions and therefore will have direct influences on the machining outcomes [7-9]. Tool wear or tool breakage can also increase the cutting forces and vibrations in the machining system, which will result in poor surface roughness, loss of the form and dimensional accuracy, and even chatter marks on machined surfaces [10]. In order to avoid such manufacturing defects or tool damages, some devices are designed and developed to measure the cutting forces and cutting dynamics. For instance, dynamometers are developed by researchers and industrial companies to measure cutting forces and the process dynamics in high precision and wide bandwidth. Currently, however, dynamometers have some limitations in their industrial application, such as their costs and reliability in stringent production environment. Furthermore, dynamometers are not applicable for layout-constrained machines and tooling setup, due to their size and weight. The dynamometer could also interfere with the cutting process and performance because of the tooling stiffness reduction in the machining system [11].

Some high value components require to be machined in a contamination-free environment, which means coolant cannot be applied during the machining. However, dry cutting condition would lead to tool wear and high cutting temperature, and poor surface quality would thus occur and tool life be shortened. Some materials, such as aluminum and magnesium alloys, are not recommended for applying direct dry-cutting, since the cutting tool is prone to suffering excessive built-up edge (BUE). So for high precision and micro machining, there is a need for new sensor technologies to be applied to further exploit and understand the cutting mechanics and machining process [6].

Based on the underlying principle and application requirements above, four types of smart tools are developed, including a cutting force based smart tool, a cutting temperature sensing oriented internally cooled cutting tool a fast tool servo (FTS), and smart collets for ultraprecision and micro machining purposes. This paper presents the design concept, development processes, application principles for the above smart tools, for high precision and micro machining in particular. The paper also explores and discusses the implementation and application perspectives of those smart tools against the smart machining requirements from a number of industrial applications, such as micromachining maintained with constant cutting force, extrahigh speed micro drilling, and contamination-free machining of medical device or explosive materials $[12,13]$.

\section{Smart Cutting Tools and Smart Machining}

Smart cutting tools are built with autonomous sensing and self-learning capabilities, and operate in-process sensoring and actuation and will thus likely lead to improved part quality and surface roughness, reduced production costs and higher manufacturing productivity. They are characterized with some distinguished features such as plug-and-play, autonomous operation, self-condition monitoring, self-positioning adjustment, selflearning, compatible with highly automated CNC environments. Four types of smart toolings have been developed by the authors as highlighted in Figure 1. They include the cutting force measurement based smart cutting tool, cutting temperature oriented smart cutting tool, fast tool servo (FTS), and the smart fixtures and smart collets, which are applicable to measure cutting force, cutting temperature, tool positioning and actuation in process, respectively or combined. The force-based smart cutting tool employs a piezoelectric film as the sensoring element, mainly using force shunt and indirect force measurement methods. The surface acoustic wave (SAW) sensor is also adopted in developing the smart cutting tool by measuring the cutting force through an alternative approach. The temperature-based smart cutting tool focuses on the development of the internally cooled cutting tool, reducing the cutting temperature

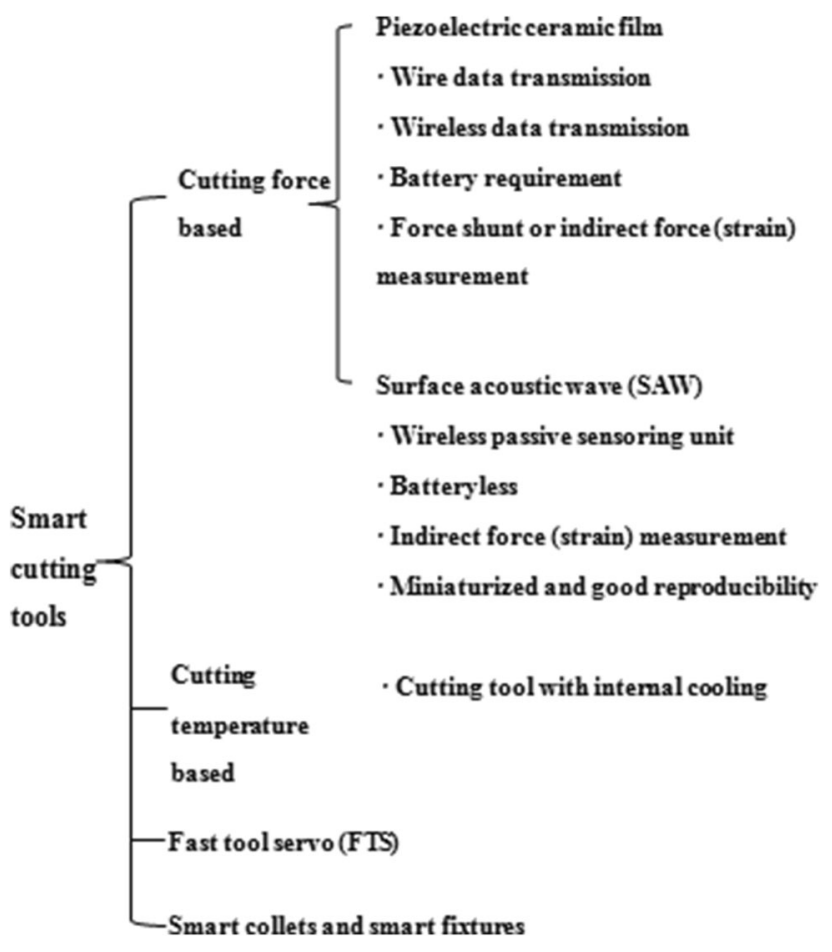

Figure 1 Family schematic of smart cutting tools 
around the cutting edge, in order to extend tool life and produce a better surface finish at the workpiece. It can also be extended for the use of measuring the cutting temperature in a specific machining environment. A fast tool servo is normally employed to position the cutting tool operating in a dynamic cutting and actuation scenario with a high precision accuracy and wide bandwidth, for precision machining of complex geometrical features in particular. Smart collets and smart fixtures are essential as enabling machining system devices for smart machining.

Smart machining has the unique manufacturing advantages, which will likely result in:

(1) Minimizing the tool paths and machining time;

(2) Improving the component surface finish;

(3) Maximizing the cutting tool life and cutting performance;

(4) Machining complex geometrized components with improved precision and efficiency, such as thin-wall structures, hollow cylinders or slender shafts;

(5) Process optimization in light of autonomous sensing;

(6) Self-learning and performance improvement in the process;

(7) Sensing of the cutting process dynamically, covering cutting forces, chip formation, and interactions at the cutting zone.

\section{Force-based Smart Cutting Tools}

\subsection{Smart Cutting Tool Using Piezoelectric Films}

\subsubsection{Design Configuration}

Cutting force can be generally measured by three methods, i.e., using force shunt, direct force measurement and indirect force measurement. Regarding direct cutting force measurement method, a sensoring unit is mounted directly in the force path in order to measure the entire process force. Conversely, the indirect force measurement method measures the force through a strain proportional to the process force [14]. For using the force shunt method, a fraction of the cutting force passing through the sensoring unit is measured. One smart cutting tool (namely, smart tool 1) as shown in Figure 2 uses the force shunt and the indirect force measurement to detect the cutting force respectively.

This type of the smart cutting tool design comprises of a cutting insert, a single-layer piezoelectric film, a metal shim and two pieces of insulation tape, as shown in Figure 2(a). The tool design considerations include [15]:

(1) The metal shim as output electrode of the piezoelectric sensor;

(2) Piezoelectric film (3 $\mathrm{mm} \times 3 \mathrm{~mm} \times 0.26 \mathrm{~mm})$, to sensor the orthogonal cutting force;

(3) The integral sensing unit is placed $6 \mathrm{~mm}$ from the cutting tip, between the cutting tool and spacer;

(4) The wire and a part of the metal shim are exposed from the cutting insert surface, but there is a safe distance from the cutting insert tool tip.

The development protocol for the smart cutting tool is summarized in a flow chart and illustrated in Figure 3.

\subsubsection{Cross-talk Analysis}

The impact hammer testing was carried out to assess crosstalk effects on the proposed smart tool 1 . The Kistler impact force hammer (Type 9722A), with the force range of 0 to $500 \mathrm{~N}$ and sensitivity of $10 \mathrm{mV} / \mathrm{N}$, is used to impact the cutting tip of the tool insert both vertically and horizontally. In order to produce a strong signal in the low frequency range, a plastic tip head of the impact hammer is applied in the hammer test. Both signal outputs from the digital impact hammer and the piezoelectric sensor were converted from the time domain into the frequency domain. The low frequency components from 0 to $50 \mathrm{~Hz}$ are the only parts to be considered in the frequency domain. Table 1 tabulates the responses from the

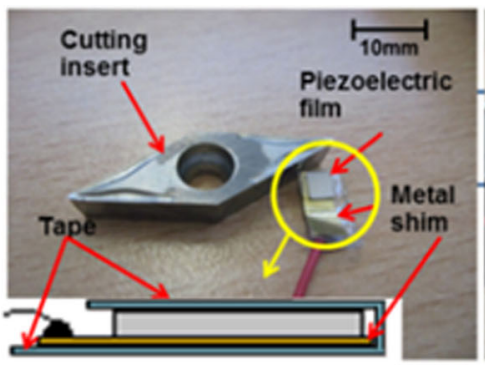

(a)

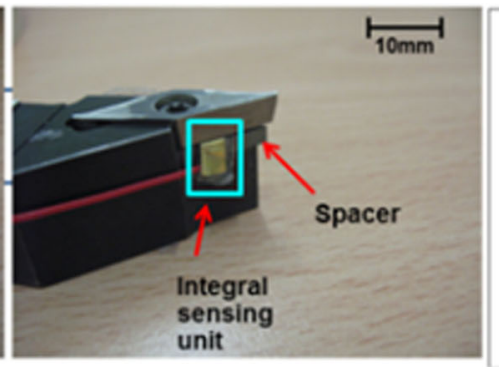

(b)

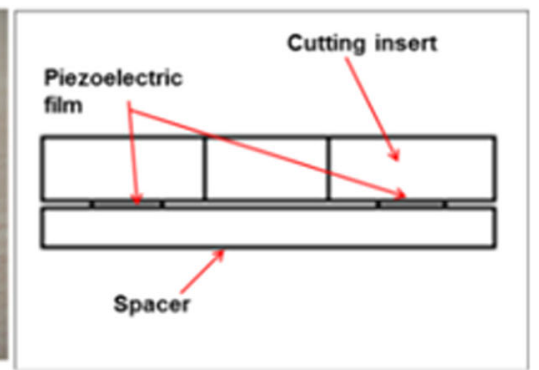

(c)

Figure 2 a Composition of the smart cutting tool; $\mathbf{b}$ assembly of the tool; $\mathbf{c}$ cross section view of the tool 
Figure 3 Illustration of the smart tool development protocol

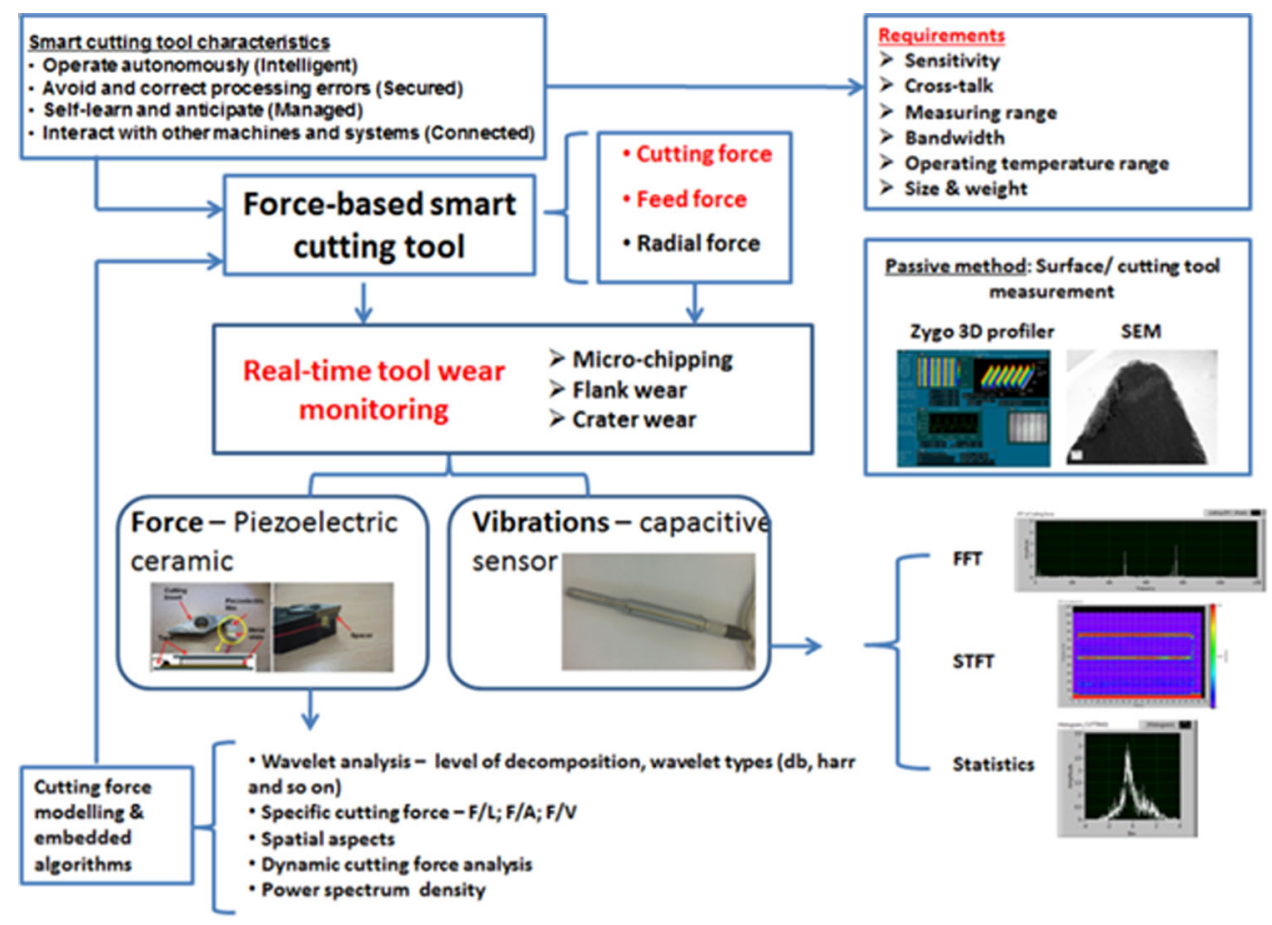

Table 1 Cross-talk of the smart tool 1

\begin{tabular}{lllll}
\hline Impact no. & Vertical piezo-sensor & Vertical impact hammer & Horizontal piezo-sensor & Horizontal impact hammer \\
\hline 1 & $2.3 \times 10^{-4} \mathrm{~V}$ & $1.2 \times 10^{-4} \mathrm{~V}$ & $4.0 \times 10^{-5} \mathrm{~V}$ & $2.5 \times 10^{-4} \mathrm{~V}$ \\
\hline 2 & $2.1 \times 10^{-4} \mathrm{~V}$ & $1.0 \times 10^{-4} \mathrm{~V}$ & $5.0 \times 10^{-5} \mathrm{~V}$ & $4.5 \times 10^{-4} \mathrm{~V}$ \\
\hline 3 & $2.0 \times 10^{-4} \mathrm{~V}$ & $1.0 \times 10^{-4} \mathrm{~V}$ & $5.0 \times 10^{-5} \mathrm{~V}$ & $4.5 \times 10^{-4} \mathrm{~V}$ \\
\hline Averaged response & $2.01 \mathrm{~V}$ & $0.12 \mathrm{~V}$ & \\
\hline Cross-talk & $5.97 \%$ & & \\
\hline
\end{tabular}

piezoelectric sensor and the digital impact hammer when the impact forces were applied vertically, which are shown in the second and third columns, and horizontally as shown in the fourth and fifth columns. At the following step, the responses of the two impacts were normalized by dividing the dynamic response of the piezoelectric sensor with the one from the impact hammer. This step was repeated three times for the three replications of the impact tests and the averages of the normalized values are obtained accordingly for the vertical and horizontal impacts respectively. Those average values are numerically compared and computed as the cross-sensitivity, which leads to $5.97 \%$ in this smart tool configuration (with piezoelectric sensors).

\subsubsection{Cutting Force Measurement Using the Smart Cutting Tools}

Two smart cutting tools were used to measure the cutting force in dry turning process. The cutting process trials are conducted under the following conditions: depth of cut varying from $0.1 \mathrm{~mm}$ to $0.8 \mathrm{~mm}$ with 0.1 $\mathrm{mm}$ increments in each pass, the feedrate of $0.15 \mathrm{~mm} /$ rev and cutting speed of $330 \mathrm{~m} / \mathrm{min}$. Figures 4(a) and 4(b) show the corresponding voltage outputs generated from the smart cutting tools using the direct and indirect force measurement methods respectively. The "steps" highlighted in red squares, are generated from impulsive engagement between the insert and the workpiece, indicate static cutting force during the machining. From Figure 4(b), it can be observed that the voltage output is increasing slightly after the "step" from the indirect force measurement and this is most likely due to the tool shank locating on its equilibrium position. In Figure 4(a), the 'step' rise signal cannot be observed due to the force shunt measurement method measuring the force directly (smart tool 1). Furthermore, the slow changing patterns of the signals after $2.5 \mathrm{~s}$ and $5.5 \mathrm{~s}$ in respective Figures 4(a) and 4(b) are not related to the cutting force, 


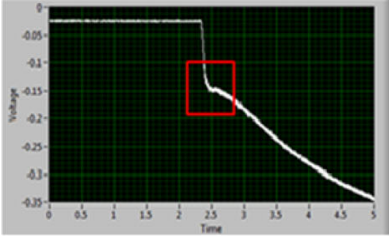

(a)

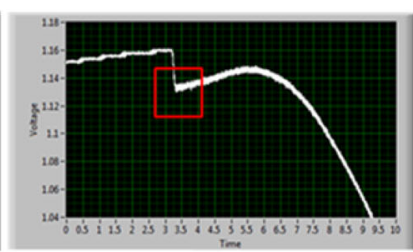

(b)

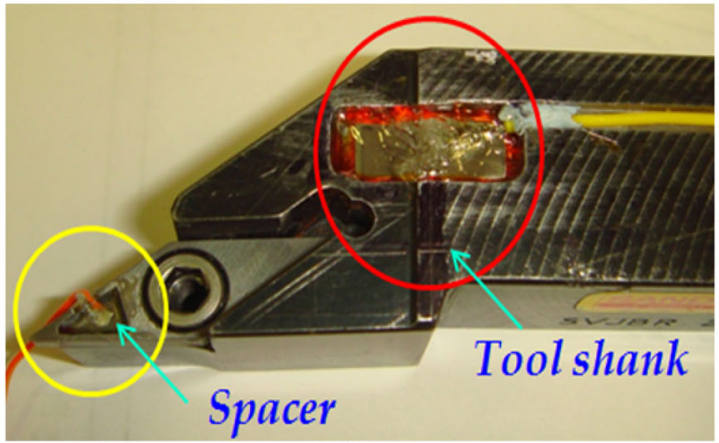

(c)

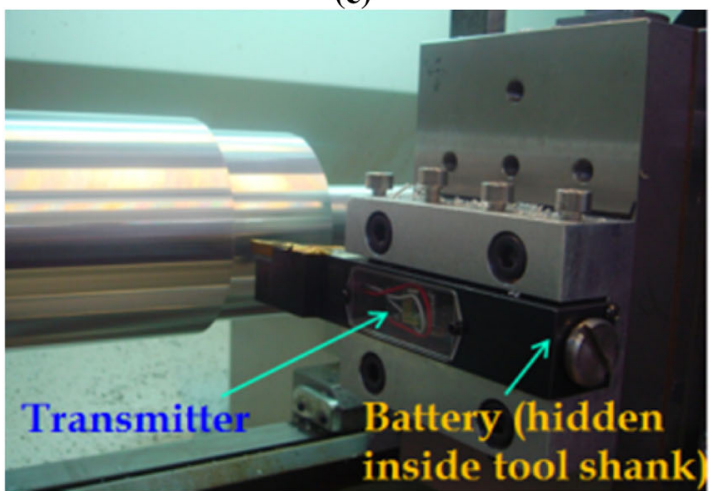

(d)

Figure 4 a Voltage output from smart tool 1; b voltage output from smart tool 2; c smart tool 2; d cutting trails illustration

but most probably due to the pyroelectric effect of the piezoelectric material.

The cutting trials were carried out in each depth of cut using cutting conditions mentioned above. The corresponding cutting forces were measured by the smart tools 1 and 2, and Kistler dynamometer (for calibration reason). Figure 5 shows the measured cutting forces using the proposed smart tools 1 and 2 respectively against Kistler dynamometer calibration simultaneously, which are in good agreement. However, signal outputs from both of smart cutting tools are affected by temperature fluctuations in real machining environment due to the temperature prone pyroelectric effect of the piezoelectric material. Therefore, surface acoustic wave (SAW) sensor as an alternative is further researched in the smart tool design and development, which may also lead to the smart cutting tool for ultraprecision and micro machining in particular.

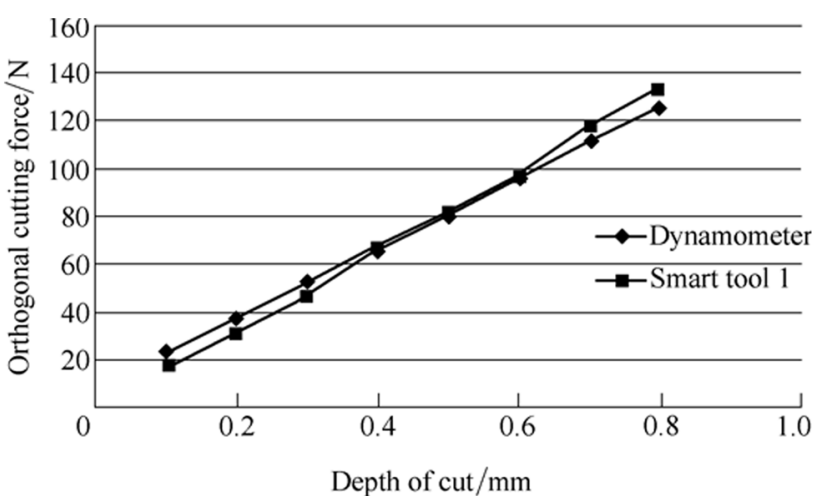

(a)

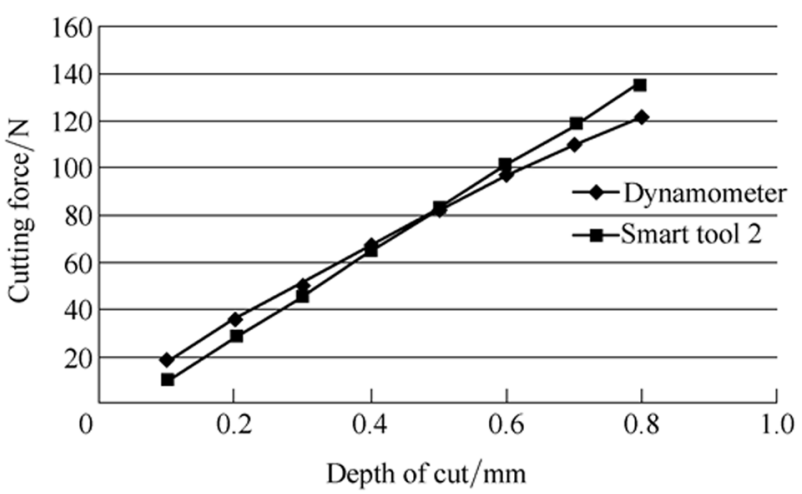

(b)

Figure 5 Cutting force measurement with a smart tool 1, b smart tool 2, and calibration against Kistler dynamometer

\subsection{Smart Cutting Tool Development Using Surface Acoustic Wave (SAW) Sensors}

\subsubsection{Smart Tool Development Using SAW-Based Force Sensor and Its FEA Simulation}

SAW based sensors are playing an increasingly important role in sensoring and measurement with diverse applications ranging from gas and vapor detection to strain measurement [16, 17]. SAW sensor technology has the potential to be applied to measure cutting forces through its indirect force measurement principle. The location of the SAW sensor is critical to minimize the pyroelelctric effect. In the smart tool design and development, the sensors are normally placed onto the tool shank, particularly at the points where the maximum strain takes place. The tool shank is usually bolted at its one end in machining, and thus over hanged and suffers strain under static cutting forces generated in the machining process. Since the relationship between the cutting force and the strain is defined, the SAW sensor is able to measure the force. The advantages of using SAW 
technology for smart tooling and smart machining application include:

(1) It is able to undertake wireless data transmission;

(2) It is possibly powerless or energized externally;

(3) High sensitivity;

(4) Working in high frequency response;

(5) It likely leads to plug-and-produce - smart integration and connectivity;

(6) Low cost.

Therefore, SAW sensor technology is applicable to monitor the tool wear and machining processes through the in-process cutting force measurement, which is increasingly beneficial to smart machining and high value manufacturing automation in the context of Industry 4.0.

Surface acoustic waves are ultrasonic waves propagating along the surface of solid objects, where there is the transmitting-receiving principle on the basis of piezoelectric transduction. An SAW sensor often consists of a large amount of electrodes, i.e., inter-digital transducers (IDTs), fabricated like comb-shapes on the top surface of a piezoelectric substrate material, such as quartz and lithium-niobate. The IDTs are functioned to convert electrical energy into mechanical energy, and vice versa, for generating and detecting the surface acoustic waves. When the cutting force is acted at the tool tip, the corresponding strain at the tool shank can be produced and detected by the SAW strain-principle sensor, as shown in Figure 6. The strain shifts the natural frequency of the surface acoustic waves away from its original one, the relationship between the cutting force and the frequency difference can thus be established as illustrated in Figure 6. The relationship between the force and frequency changes can be expressed by Eqs. (1) and (2):

$\varepsilon=-\frac{h}{2} \frac{F(L-x)}{I E}$,

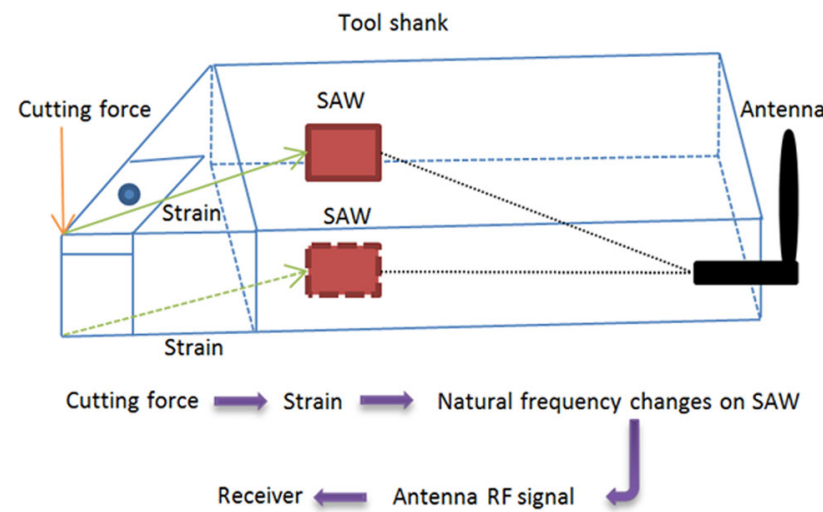

Figure 6 Schematic illustration of the principle using SAW sensors on the tool shank to detect cutting forces
$\Delta \mathrm{f}=2 \mathrm{~S}_{\mathrm{G}} \cdot \varepsilon$.

Where $h, b, L$ represent the thickness, width and length of the tool shank respectively. $\Delta f$ is the natural frequency change of the SAW strain sensor, $x$, the distance between the SAW and the fixed end. $E$ and $I$ represent the Young's modulus and the second moment of area at the tool shank.

The piezoelectric performance of the SAW sensor is represented with Eqs. (3) and (4) below. The FEA simulation, set up under accurate boundary conditions, is carried out to investigate a variety of proposed design structures so as to obtain a scientific understanding on the SAW strain performance of the sensors when being applied as the cutting force sensors.

$\boldsymbol{T}=\boldsymbol{C}^{\boldsymbol{E}} * \boldsymbol{S}+\boldsymbol{e} * \boldsymbol{E}$,

$\boldsymbol{D}=\boldsymbol{e}^{t} * \boldsymbol{S}+\boldsymbol{\varepsilon}^{s} * \boldsymbol{E}$.

Where $\boldsymbol{T}$ is the stress vector and $\boldsymbol{S}$ is the strain vector, both has six elements including $x, y, z, x y, y z, x z . \boldsymbol{D}$ is the electric displacement vector and $\boldsymbol{E}$ is the electric field vector, both has three elements including $x, y, z) . \boldsymbol{C}^{\boldsymbol{E}}$ is the stiffness matrix being evaluated in the constant electric field, i.e., short circuit. While $\boldsymbol{e}$ is the piezoelectric matrix relating to stress electric field, $\boldsymbol{e}^{t}$ is the piezoelectric matrix relating to stress electric field (transposed) and $\boldsymbol{\varepsilon}^{s}$ represents the dielectric matrix evaluated at constant strain, e.g., clamped mechanically.

The SAW strain sensor substrate is made of quartz with a STX cut and the electrodes are made from Al. Rayleigh waves can be generated using the quartz-STX with a velocity of $3158 \mathrm{~m} / \mathrm{s}$. Moreover, the energy of the Rayleigh wave is confined close to the surface and dies out within two or three wavelengths in depth from the surface. The resonant frequency of the SAW is chosen to be $433 \mathrm{MHz}$. Based on the resonant frequency $(f r)$ and the velocity $(V)$, the elastic wavelength $(\lambda)$ can be determined by

$\lambda=\frac{V}{f r}=\frac{3158 \mathrm{~m} / \mathrm{s}}{433 \mathrm{MHz}}=7.29 \mu \mathrm{m}$.

The distance between the successive IDT electrodes $\mathrm{P}$ is $3.645 \mu \mathrm{m}$, which is half of the elastic wavelength. The geometric parameters of the SAW structure applied in the simulation are summarized and highlighted in Table 2 .

Table 2 Geometry of the SAW sensor substrate and IDT

\begin{tabular}{ll}
\hline Components & Geometry $/ \mu \mathrm{m}$ \\
\hline Substrate thickness & 15 \\
Periodicity of electrode & 7.29 \\
Width of electrode & 1 \\
Al electrode thickness & 0.2 \\
\hline
\end{tabular}




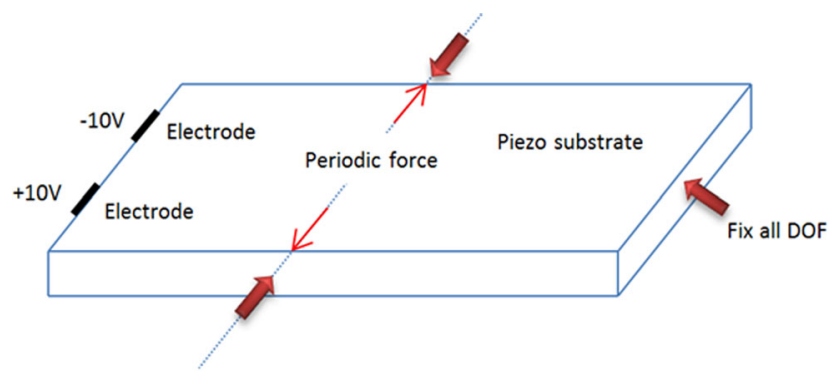

Figure 7 Boundary conditions defining the propagation for the FEA simulations

In developing FEA simulation for the SAW strain sensor, the boundary conditions for the simulation, as shown in Figure 7, need to be defined accurately. The material properties for both the piezoelectric substrate and the $\mathrm{Al}$ electrodes should be defined accurately as well. The stiffness matrix, the piezoelectric matrix, and the permittivity matrix are required as inputs into the FEA simulation. Young's modulus, the Poisson's ratio and the density are essential data as the inputs for the $\mathrm{Al}$ electrodes. The modal analysis is carried out to determine the modal frequencies and corresponding mode shapes so as to choose the proper propagation wave mode travelling along the substrate. The simulation can also be used as the starting point for further harmonic analysis to find out the corresponding dynamic response in the frequency components of interest. The modal analysis is performed to show several mode shapes and modal frequencies. The 8 th mode shape and its corresponding modal frequency of $465 \mathrm{MHz}$ are found to be the preferred propagation wave mode as shown in Figure 8, since the wave only propagates near the surface and maximally penetrates about $1.2 \lambda$ below the surface. This agrees with the Rayleigh waves theory [18].

In the harmonic analysis, an $\mathrm{AC}$ voltage of $10 \mathrm{~V}$ is applied onto one electrode, with a range of frequencies from $464 \mathrm{MHz}$ to $472 \mathrm{MHz}$ around the modal frequency obtained in the previous analysis. The resonant peak is obtained in the modal frequency of $465 \mathrm{MHz}$ with a dynamic response of $0.16 \mu \mathrm{m}$ as shown in Figure 9. The

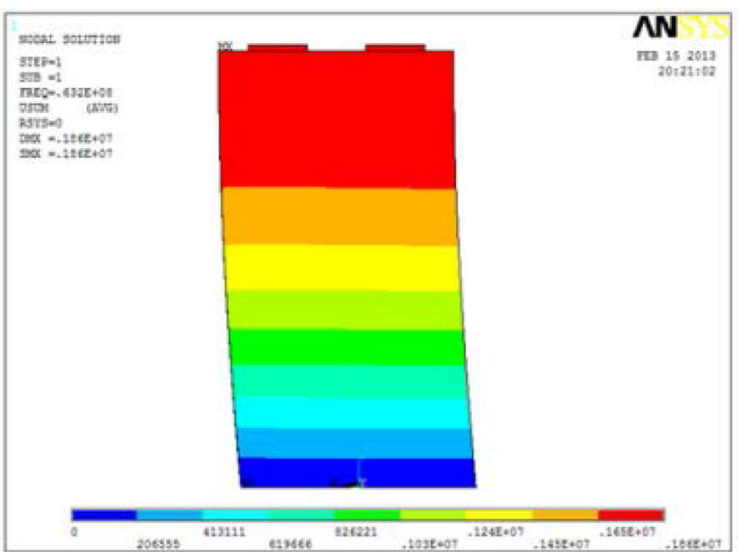

$1^{\text {st }}$ mode shape $-63.2 \mathrm{MHz}$

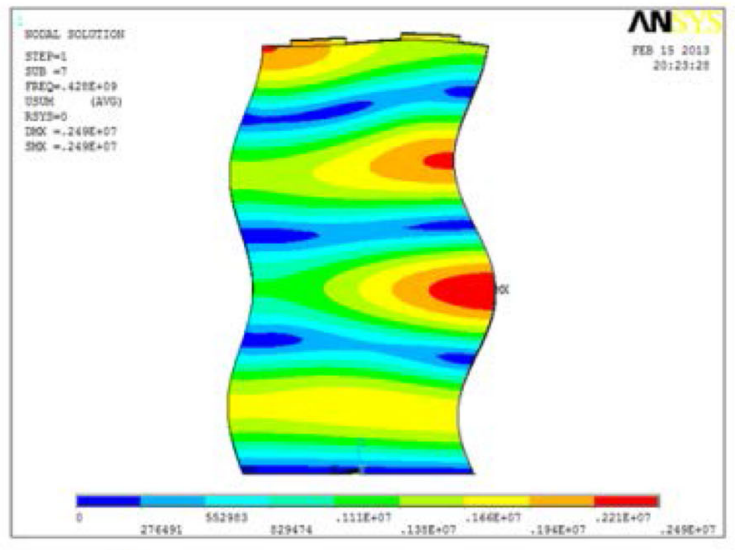

$7^{\text {th }}$ mode shape $-428 \mathrm{MHz}$

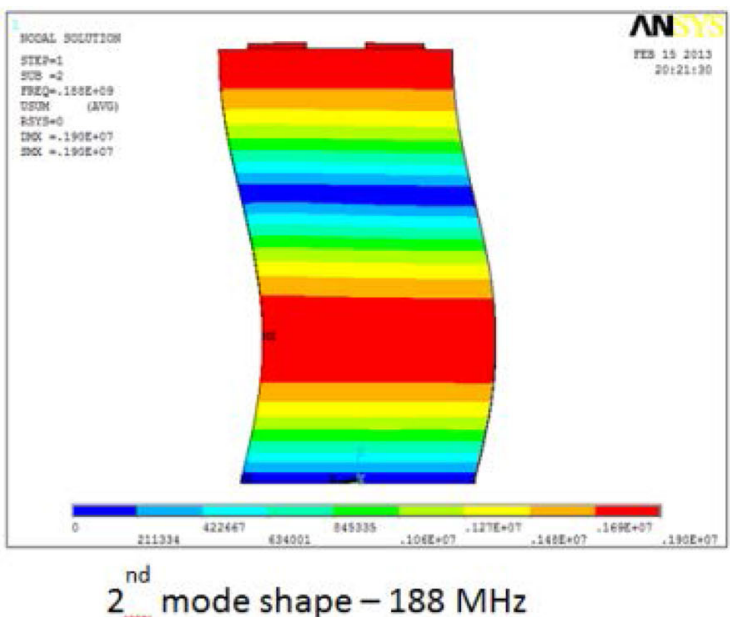

$2^{\text {nd }}$ mode shape $-188 \mathrm{MHz}$

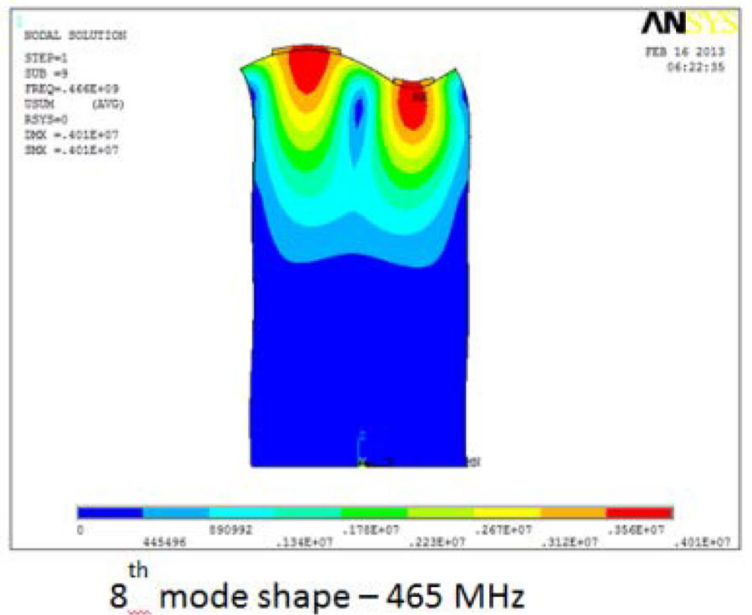

Figure 8 The 8 th mode shape at $465 \mathrm{MHz}$ and other modes for the SAW sensors 


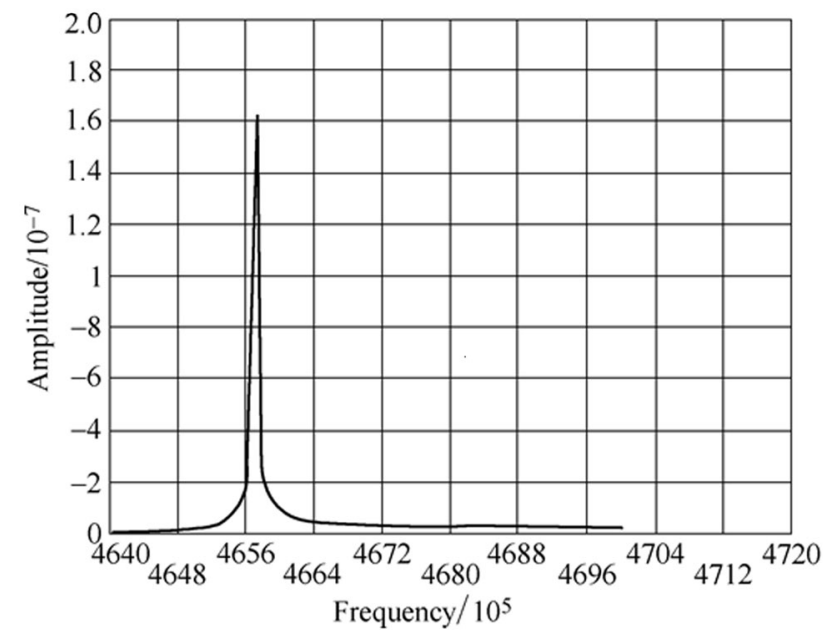

Figure 9 Frequency response of the SAW in the harmonic analysis

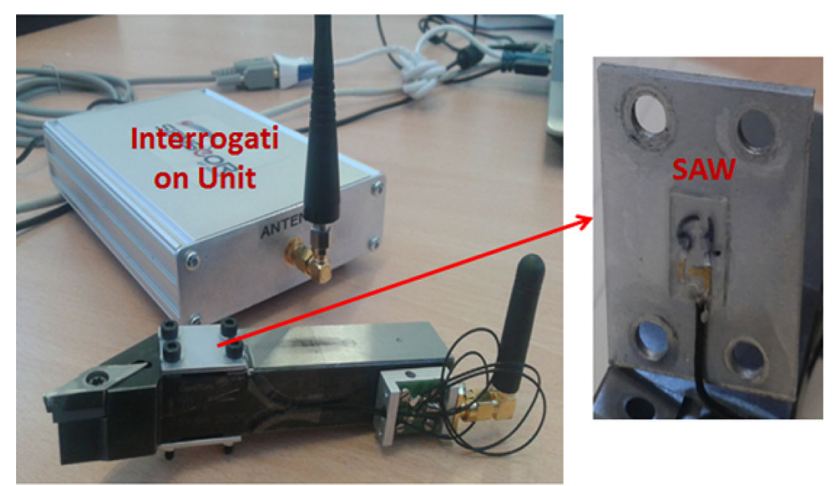

Figure 10 SAW strain sensors instrumented onto the cutting tool shank

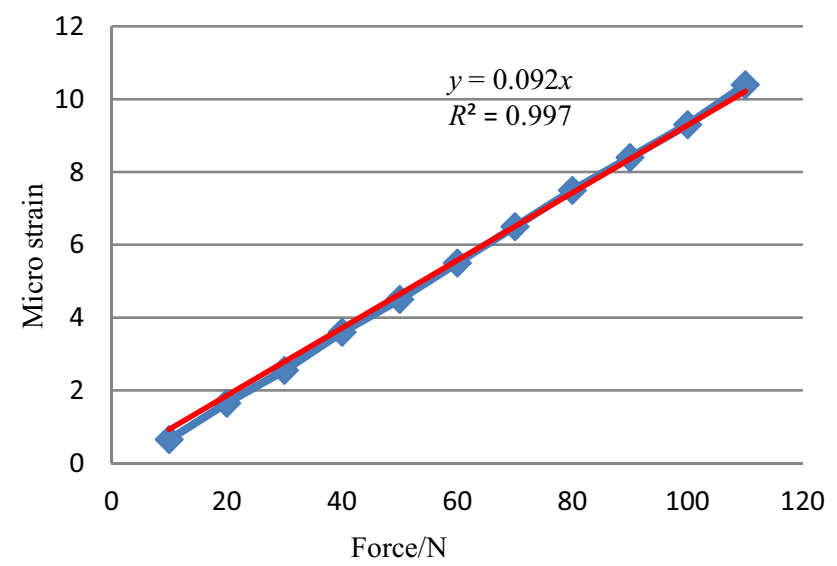

Figure 11 Correlation between static force and strain output

results of the simulation have been extended to support the experimental implementation of attaching SAW sensors onto the tool shank and calibrating their utilization for cutting force measurement.

\subsubsection{Experimental Implementation}

The two SAW sensors are mounted onto two aluminum plates which are firmly bolted to the top and bottom side of the tool shank respectively, as shown in Figure 10. The advantage of this design configuration is that it can make the SAW devices reusable and reduce the amount of heat generated during the cutting process and its transferring to the SAW devices, and therefore avoid their failure. Furthermore, the proposed half bridge design configuration can theoretically produce characteristics of temperature compensation. It makes the traction and torque compression compensations be possible, as the SAW gauges orientation leads the loading having no side-effect.

For evaluating and validating the SAW-based smart cutting tool for cutting force measurement in real machining environment, calibration is carried out so as to establish the scientific understanding of the intrinsic relationship between the SAW strain and the cutting force.

A pre-defined static force as indicated and defined with a force gauge FT 200, is applied at the cutting tool tip so as to generate a corresponding strain to be measured by the SAW sensor. Figure 11 shows the linear relationship between the applied force and the strain output in the range of $0-120 \mathrm{~N}$, which is due to the elastic deformation of the

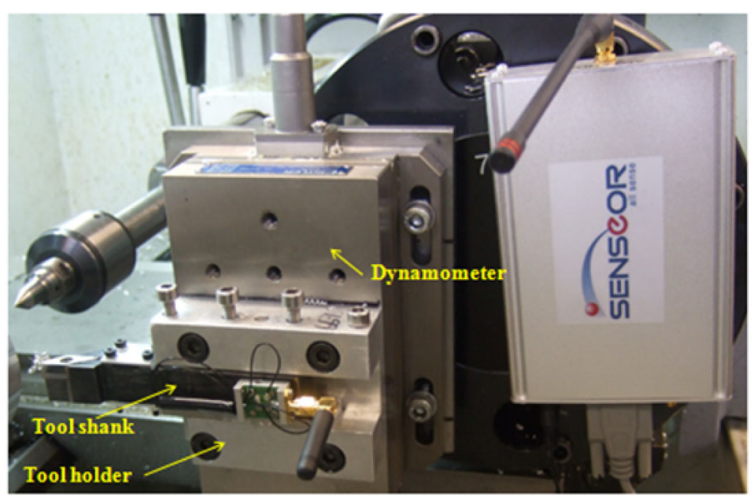

(a)

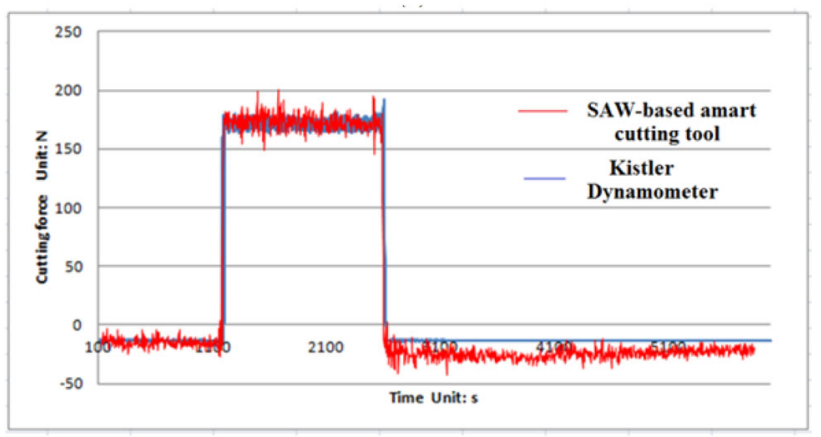

(b)

Figure 12 a Experimental setup; $\mathbf{b}$ cutting forces measured by the SAW-based smart cutting tool and Kistler dynamometer 
Figure 13 a Experimental setups; b modelling of the internally channeled cutting insert; c comparison of tool temperature in both un-cooled and internally cooled cutting scenarios

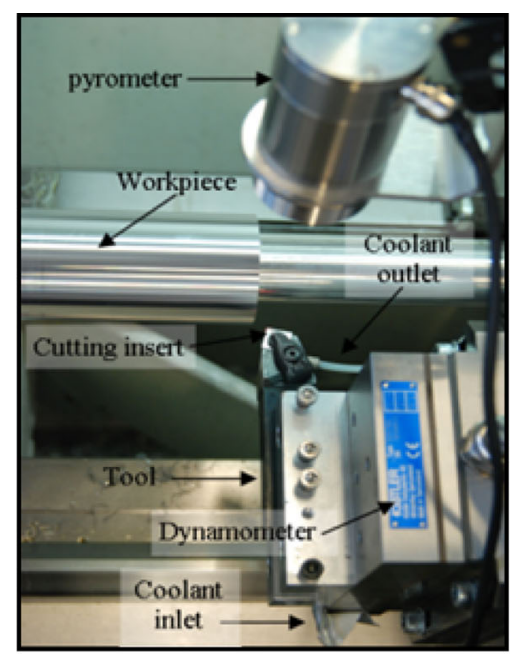

(a)

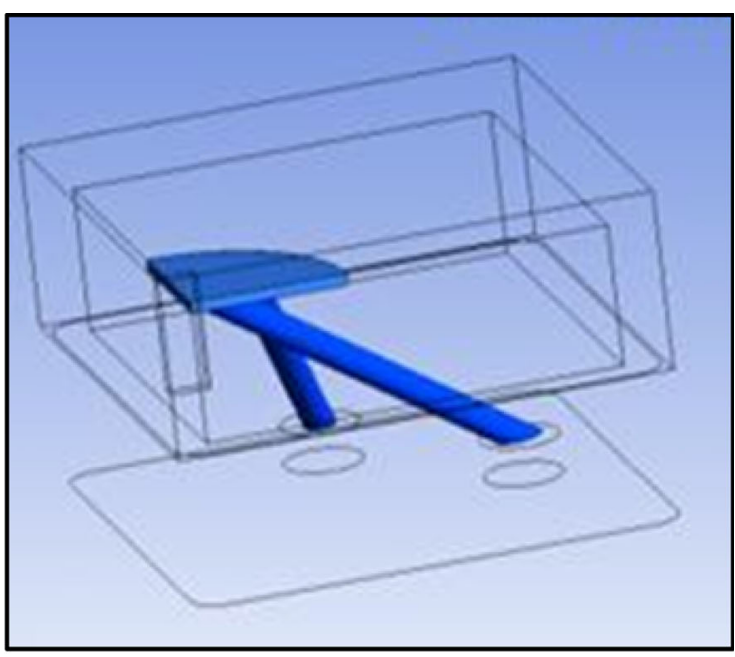

(b)

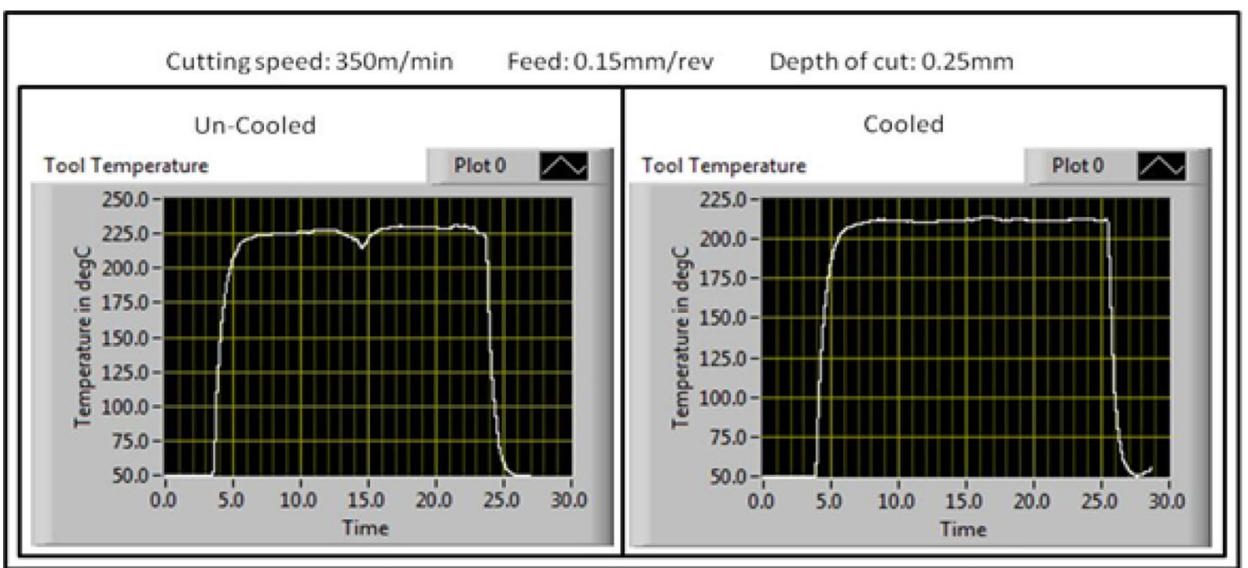

(c)

tool shank [19]. The curve fitting also leads to the expression equation for representing the relationship between the applied force and the strain, with a considerably high correlation, i.e., $R^{2}$ value of 0.9968 .

\subsubsection{Preliminary Machining Trials}

The SAW-based smart cutting tool is used to determine the cutting force in dry turning process, in the machining conditions: the depth of cut, $1 \mathrm{~mm}$, constant federate at 0.2 $\mathrm{mm} / \mathrm{r}$, and a spindle speed at $900 \mathrm{r} / \mathrm{min}$. Figure 12(a) shows the experimental setup with the tool shank mounted on top of the Kistler dynamometer and the interrogation unit communicating with the SAW-based smart cutting tool. Figure 12(b) shows the comparison of the cutting force measurement results by using the SAW-based smart tool and the Kistler dynamometer. The signal pattern captured by the smart cutting tool is in good agreement with the one by Kistler dynamometer.

\section{Design of Cutting Temperature-based Smart Cutting Tools}

The increase in cutting temperature normally causes the premature cutting tool failure or excessive tool wear, while most of the wear processes occurs at the major flank face and rake face of the cutting tool. There are four main wear mechanisms in association with tool failure, including: oxidation, abrasion, adhesion and diffusion. All of these wears are related to the temperature sensitivity even under normal cutting conditions [20,21]. At low cutting temperature (due to soft cutting or high cooling efficiency), adhesive and abrasive wears are dominant. While the cutting temperature is higher than a certain threshold, thermal induced wear, such as oxidation and diffusion, are activated and dominate total wear. The utilization of cutting fluid, traditionally applied to remove heat generated from the cutting process, can additionally cause environmental pollution, health hazards, surface contamination and an 
increased cost of production [22]. The above issues can be avoided by using an internally-cooled smart cutting tool.

Figure 13(a) shows the experimental setup, a pyrometer for measuring the temperature at the cutting tip and the Kistler dynamometer for measuring the cutting force in three directions during dry machining of the aluminum workpiece using an internally-cooled smart cutting tool developed by authors. As shown in Figure 13(b), at the internally-cooled cutting tool, micro-channels (coolant inlet and outlet) are machined within the solid cutting insert, which are close to the cutting tip where the maximum heat being generated. The micro-channels are designed to achieve optimal cooling performance, while maintaining the sufficient mechanical strength of the cutting tool. Pure water, functioning as the cooling fluid, is pumped through micro-channels to reduce the temperature near the cutting tip. The tool temperature reaches $225^{\circ} \mathrm{C}$ in machining the aluminum workpiece (cutting speed: 350 $\mathrm{m} / \mathrm{min}$; feedrate: $0.15 \mathrm{~mm} / \mathrm{rev}$ and depth of cut: $0.25 \mathrm{~mm}$ ). However, the temperature drops to $210{ }^{\circ} \mathrm{C}$ (Figure 13(c)) when the internal coolant is applied. It is possible to maintain the tool within a 'safe' cutting temperature range by using such a smart tool. As discussed above, the cutting temperature affects the tool wear albeit the observed total wear is not necessarily linked with the cutting temperature in all cases. The cutting trials results indicate that using the internally-cooled smart cutting tool can reduce the cutting temperature and activation of adhesion, oxidation and diffusion wears; and lead to an optimum cutting temperature which can minimize tool wears development.

Although more experimentation and machining trials need to be undertaken for further validation, internallycooled smart cutting tools can be applied in the following applications:

(1) Adaptive smart machining of high value components;

(2) Contamination-free machining such as medical devices and explosive materials;

(3) Machining of difficult-to-machine materials including titanium, magnesium and Inconel alloys, etc.

\section{Fast Tool Servos (FTS)}

Fast tool servos (FTS) play an important role in precision turning of micro-featured or free-form surfaces with a diamond cutting tool. The FTS system normally includes a piezoelectric (or voice coils) actuator, flexure hinges, and positioning feedback sensor as illustrated in Figure 14 [23]. The piezoelectric actuator is a critical component in the FTS system and designed to perform precision positioning of the cutting tool during short stroke turning operations.

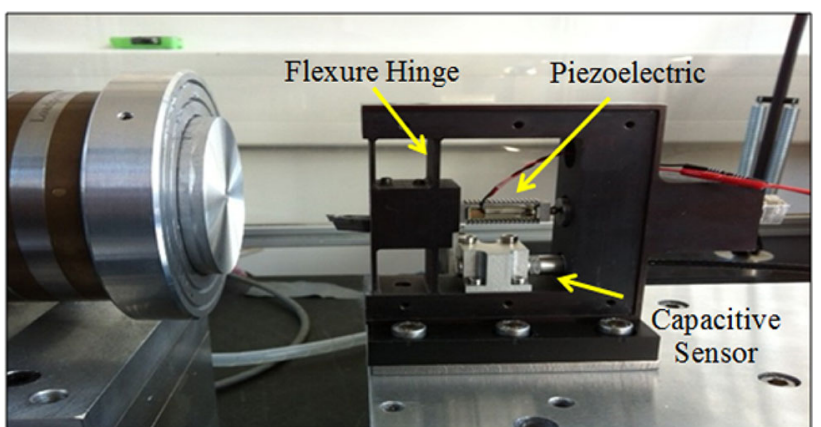

Figure 14 Fast tool servo mounted on the micro turning machine

Furthermore, the piezoelectric actuator is selected as the driving element because of its high frequency oscillation operation capability. Static deformation of the FTS structure caused by cutting forces during rough and finish machining, must be minimized to reduce the form and dimensional errors of the component. Therefore, high stiffness, which affects the machined surface directly, is required particularly in the feed direction. A high natural frequency and anti-fatigue is required in the FTS structure design so as to prevent its resonant vibrations particularly caused by cutting forces. On other hand, the high stiffness of the FTS structure is helpful in reducing the effective stroke of the piezoelectric actuator to some extent. For this reason, a compromise is made between the high stiffness and actuator stroke reduction [24]. Figure 15(a) shows the FTS system off-line testing, using some equipment such as the capacitive sensor unit, signal generator, and the voltage amplifier/supplier for driving the actuator.

Based on the design criterion discussed above, the FTS developed can achieve a natural frequency of $1866.5 \mathrm{~Hz}$ (FEA simulation), as shown in Figure 15(c). In the experimental testing and implementation, impact force is horizontally applied onto the hinge of the FTS structure with an impact hammer and the corresponding dynamic response is acquisited using the capacitive displacement sensor as shown in Figure 15(e). In Figure 15(f), the fundamental natural frequency is $1840.3 \mathrm{~Hz}$ as detected using the impact hammer testing technique. There is a close agreement on the fundamental natural frequency between the FEA and experimental results with an error of $1.4 \%$. Multi-physics analysis is investigated on the interaction between the piezoelectric actuator and FTS structure. As the piezoelectric actuator is driven by a DC voltage $30 \mathrm{~V}$, the corresponding stroke length is $3.829 \mu \mathrm{m}$ as shown in Figure 15(d). Moreover, the static stiffness of the FTS developed is computed in $10.88 \mathrm{~N} / \mu \mathrm{m}$. The machine stiffness loop of the micro turning machine can be estimated as shown in Figure 14.

A high machine loop stiffness, $12.14 \mathrm{~N} / \mu \mathrm{m}$, is required in order to prevent the machining chatter and to minimize 
Figure 15 a Experimental setup for using the FTS;

b micro-featured surface machined by using the FTS developed; c modal analysis; d multi-physics analysis on the FTS structure and piezoelectric actuator; e impact hammer testing on the FTS structure; and f modal frequency of the FTS structure

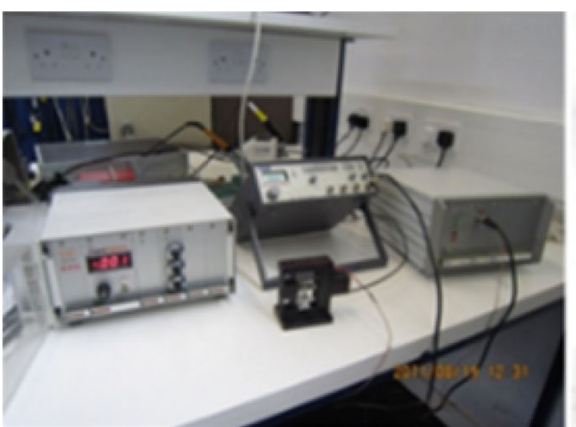

(a)

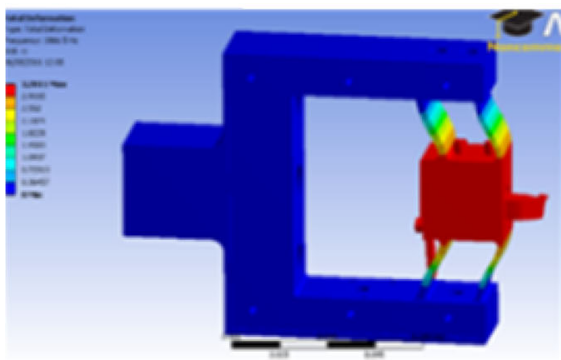

(c)

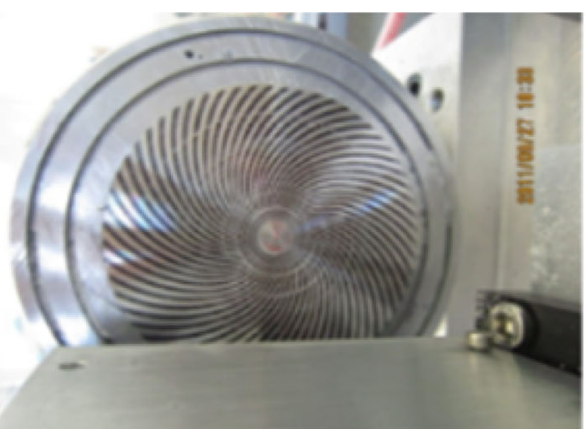

(b)

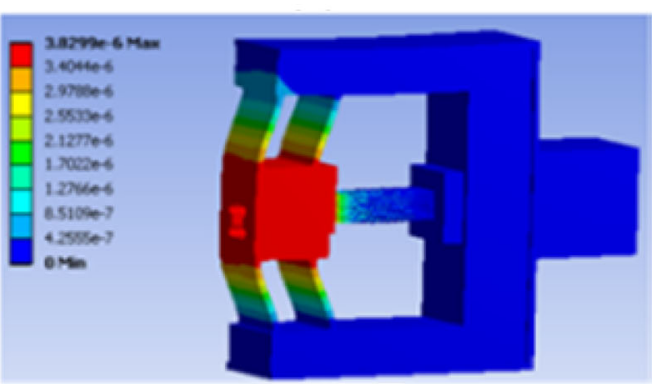

(d)

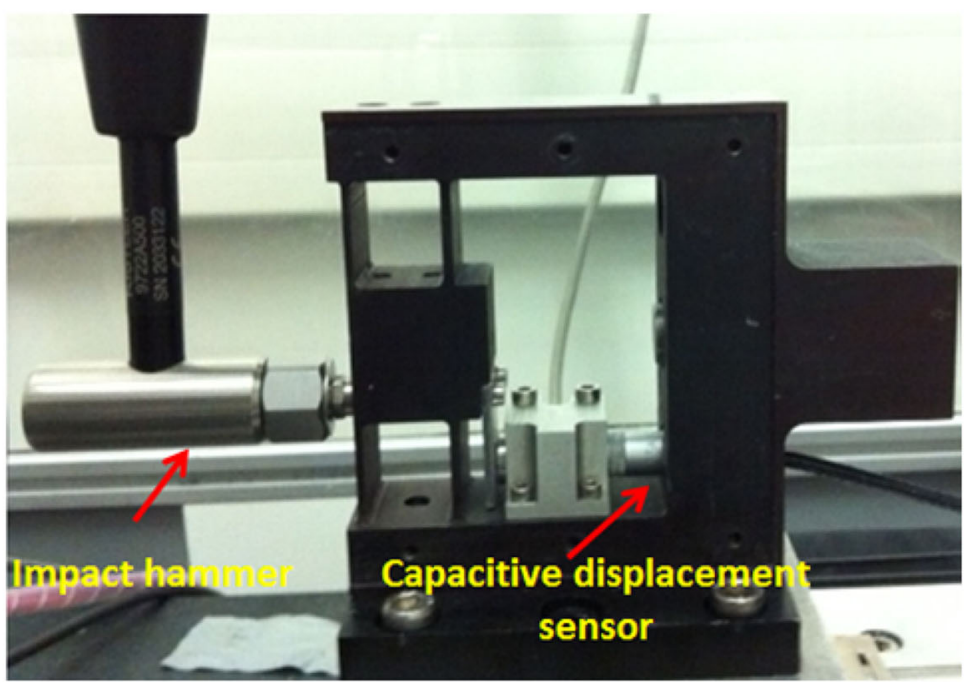

(e)

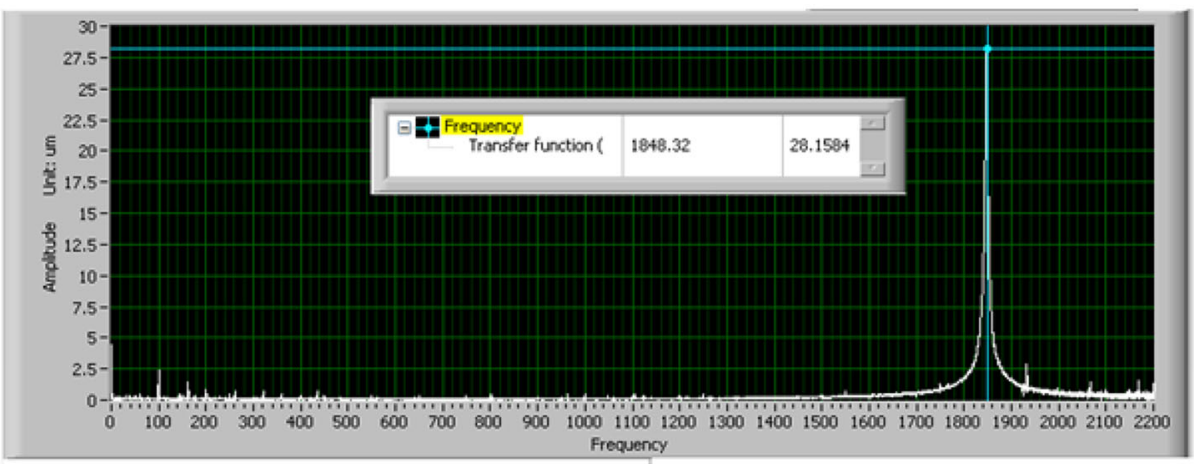

(f) 
the geometric error of the component. The detailed analysis is as follows:

(1) Axial stiffness of the spindle: $K_{\text {spinlde }}=40.00 \mathrm{~N} / \mu \mathrm{m}$

(2) Lateral stiffness of the air bearing slide: $K_{\mathrm{X} \_}$Slide_Z $=$ $40.00 \mathrm{~N} / \mu \mathrm{m}$

(3) Axial stiffness of the tool holder: $K_{\text {Tool_holder }}=$ $K_{\text {Flexure }}+K_{\text {Piezo }}=10.88 \mathrm{~N} / \mu \mathrm{m}+20.00 \mathrm{~N} / \mu \mathrm{m}=30.88$ $\mathrm{N} / \mu \mathrm{m}$

Therefore, the total machine loop stiffness is

$$
\begin{aligned}
1 / K_{\text {Total_loop }} & =1 / K_{\text {spinlde }}+1 / K_{\mathrm{X} \_S \text { Slide_Z }}+1 / K_{\text {Tool_holder }} \\
& \Rightarrow K_{\text {Total_loop }}=12.14 \mathrm{~N} / \mu \mathrm{m}
\end{aligned}
$$

Preliminary cutting trials are carried out for machining micro-featured surface pattern on an Al workpiece using the FTS in the face turning process shown in Figure 15(b). The FTS can be considered as one type of smart tool systems to position the tool precisely and dynamically, which is essential for machining micro-structured surfaces and special-featured components.

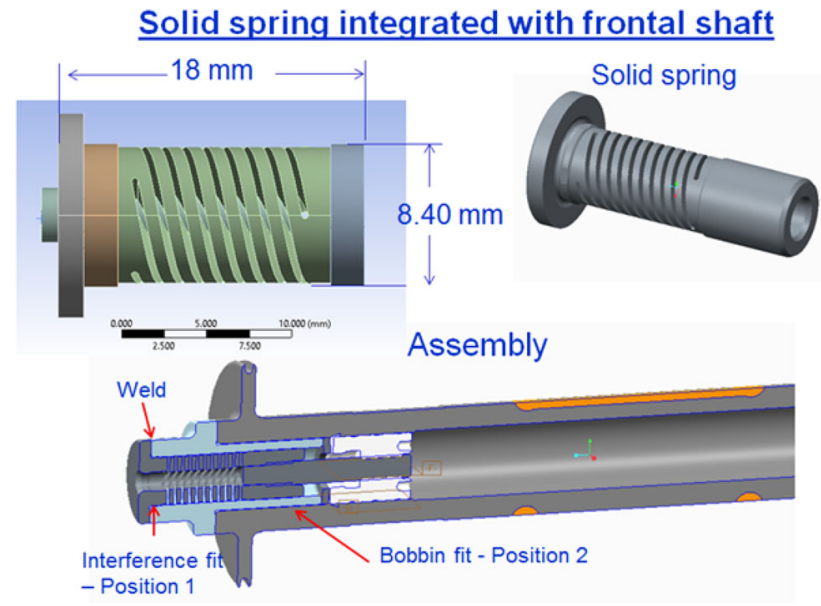

Figure 16 Design layout of an automatic collet for high speed micro milling or micro drilling

\section{Pull-Release tool holder ( $2^{\text {nd }}$ design $)$}

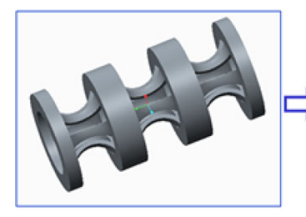

3D ProE mode
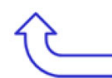

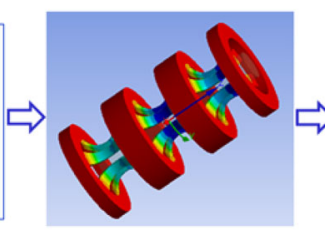

FEA simulation Machining \& Assembly
Optimization

Figure 17 Design of the pull-release tool collet for high speed micro drilling spindles

\section{Smart Collets and Smart Spindles}

Through an industrial project engagement, the authors have developed the smart collets to be fitted with high speed precision spindles for smart micro drilling and micro milling purposes. For instance, Figure 16 illustrates the design of an automatic loading smart collet, which can be applicable and essential to undertaking high speed micro drilling or micro milling spindles operating in an industrial scale.

An alternative design of the automatic collet for high speed spindles is illustrated in Figure 17, which shows the design and development principles, i.e., being able to fulfill automatic loading and unloading the micro tools in an industrial operation environment. The collets can also be integrated with sensoring capacities, such as micro cutting forces or torques, which are desired for development of smart spindles and smart machines. They collectively together provide the enabling technology for undertaking smart micro manufacturing particularly in industrial operation environment.

\section{Smart Machining - Application Exemplars}

The smart tool 1 developed by authors, can provide real time in-process data on cutting forces. It renders a compact low cost sensoring tool configuration with the plug-andproduce feature. The innovative concept and utilization of the smart cutting tool and the associated embedded algorithms are further studied for smart machining processes. In particular, using adaptive computer control (ACC) to maintain the constant cutting force with varied depths of cut is experimentally tested. The test is encouraging and promising, as it likely enables:

(1) Protecting and enhancing the tool when the measured force is greater than the reference force;

(2) Maintaining high productivity when the measured force is less than the reference force, and;

(3) The improved reliability of the smart cutting tools in smart machining applications [25].

Figure 18(a) illustrates a block diagram of a CNC machine with adaptive control, where the adaptive control process is based on the smart cutting tool in-process measuring cutting force. Through LabVIEW programming, the adaptive smart machining system is prototyped, which can perform self-monitoring and optimize their operations. For instance, it can determine whether the current cutting parameters are optimal and then adapt with the optimal process setups to operate the precision turning machine as needed. The test machining system includes a communication interface for extracting current cutting parameters. 


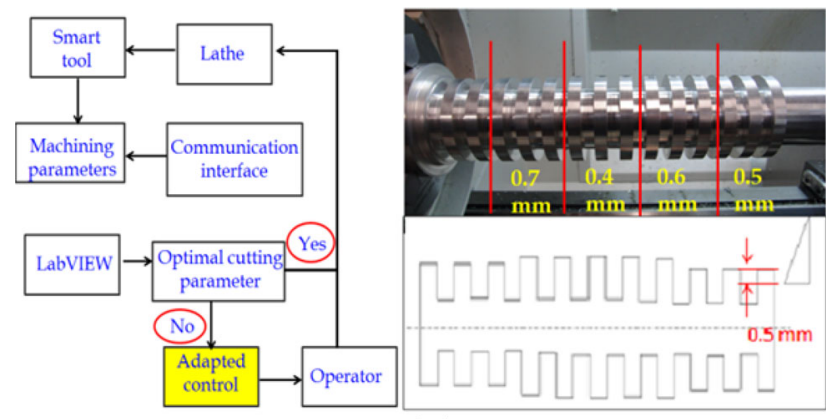

(a)

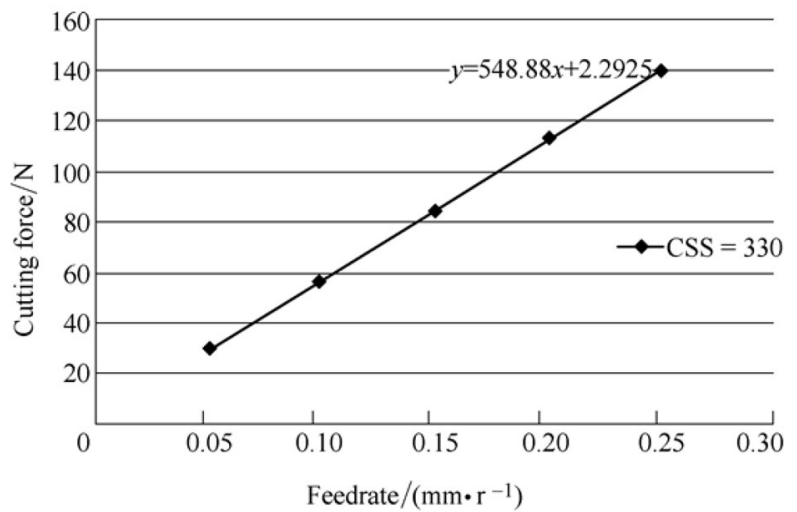

(b)

Figure 18 a Adaptive control loop and adaptive smart machining trails on a CNC machine; $\mathbf{b}$ the relationship between the federate and cutting force

The prototype system, including the smart cutting tool and the associated algorithms, is tested with cutting trials on the well-designed component as shown in Figure 18(a). Figure 18(b) illustrates the linear relationship between cutting force and feedrate at the constant surface speed of 330 $\mathrm{m} / \mathrm{min}$ and depth of cut of $0.5 \mathrm{~mm}$. Furthermore, the equation is provided on describing this linear relationship using curve fitting technique. As a result, if the cutting parameters require a depth of cut of $0.5 \mathrm{~mm}$, a feedrate of $0.15 \mathrm{~mm} / \mathrm{rev}$ with a constant surface speed of $330 \mathrm{~m} / \mathrm{min}$, the actual cutting force should be $84 \mathrm{~N}$, as observed from Figure 18(b), when the cutting tool is in good condition. However, due to the variation of the dynamic cutting force amplitudes, the cutting force is chosen to lie within the control range of $79 \mathrm{~N}$ to $91 \mathrm{~N}$.

Figure 19(a) demonstrates a LabVIEW based userinterface for communicating and adaptive control with CNC control system, which is developed to enable extracting cutting process data, such as feedrate, constant surface speed, depth of cut, and spindle speed. The interface system also records the main cutting force using the smart cutting tool signals obtained during the machining process. The measured cutting force is then compared with the desired cutting force range, in order

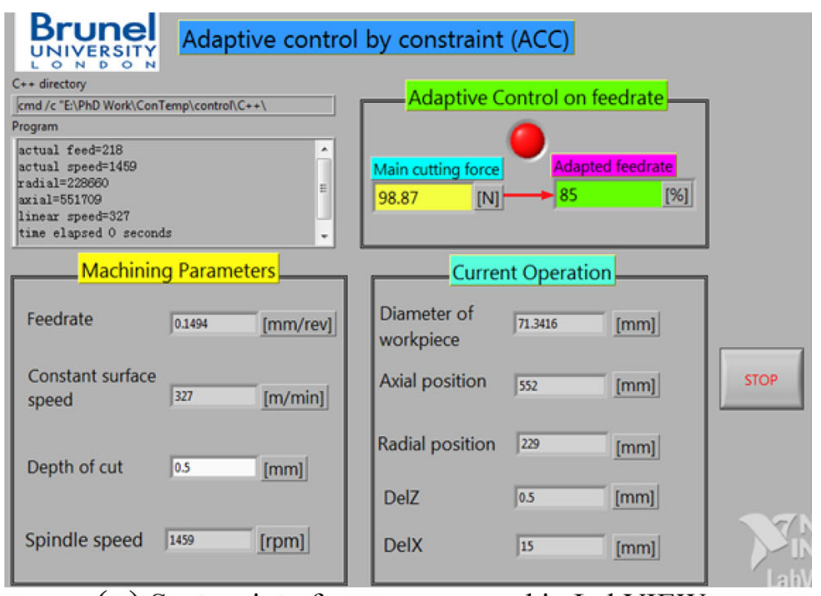

(a) System interface programmed in LabVIEW

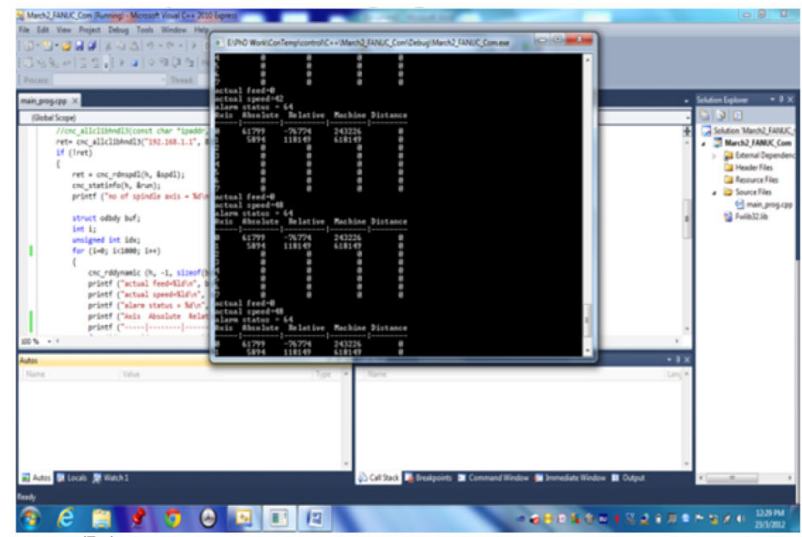

(b) Communication with the Fanuc control system

Figure 19 Illustration of the system user-interface and its communication with the $\mathrm{CNC}$ controller

to adapt the operational feedrate to be an optimal one (as illustrated in Figure 18(b)). In order to extract the cutting parameters from the CNC turning machine (ALPHA 1350XS), $\mathrm{C}++$ programming is developed and integrated into the LabVIEW interface. The function of the $\mathrm{C}++$ programming is to manage the data transmit/receive sequence, based on IP addresses with the CNC lathe through Ethernet, and then to obtain the cutting parameters using proprietary coding provided from the Fanuc library. Partial communication sequence is shown in Figure 19(b). When the main cutting force of $98.87 \mathrm{~N}$ drops outside of the pre-defined control range of $79 \mathrm{~N}$ to $91 \mathrm{~N}$, the adaptive control works out the adapted feedrate to be $85 \%$ of the previous feedrate, in order to maintain a constant cutting force.

Through the case study and discussion above, it can be found that the adaptive smart machining with smart cutting tools likely enable the machining process:

(1) to operate autonomously (Intelligent) in a smart manner. 
(2) to avoid and correct processing errors in process (Secured).

(3) to self-learn from the real-time data and anticipate the dynamic changes (Managed).

(4) to interact with other machines and systems (Connected), while operating on the shop-floor manufacturing cell and system.

ISMC (Intelligent, Secured, Managed and Connected) represents the essential features of smart machining processes enabled by smart toolings (smart cutting tools, smart collets and smart fixtures, etc.). ISMC is the essential and dispensable design rules and fundamentals in developing smart toolings and adaptive smart machining systems.

\section{Conclusions}

A number of smart tools, including cutting force-based smart cutting tools, cutting temperature-based tools, FTS and smart collets/fixtures are presented in this paper. The design concepts of the force-based smart cutting tools are proposed using the piezoelectric film based on the force shunt measurement and the indirect force measurement methods. With the depth of cut from $0.1 \mathrm{~mm}$ to $0.8 \mathrm{~mm}$, a close agreement on the orthogonal cutting force measurement can be achieved by using Kistler dynamometer and the two respective smart cutting tools developed. In order to achieve higher accuracy and more reliable measurement, SAW-based smart tooling development is exploited with the application to ultraprecision machining. Based on modelling and simulation analysis, a better understanding of SAW-based sensors is obtained and used to optimize the practical design of the SAW-based smart cutting tool. The experimental results from machining trials show close agreement between the Kistler dynamometer and the SAW-based smart cutting tool on the main cutting force measurement. The preliminary cutting trials using the internally cooled smart cutting tool have demonstrated the temperature of the cutting tip can be reduced by pumping the coolant through internal micro-channels within the smart cutting tool. Smart collets are also presented in line with requirements for smart spindles and high precision micro drilling and milling application. Further in-depth research for the internally cooled cutting tool is carried out particularly on its applications in adaptive machining. In the final part of this paper, one of the presented smart tools was used in smart machining by using adaptive control to maintain the cutting force constant with varied depths of cut by adapting the federate, which can be used particularly in machining components made from hybrid materials or hybrid structures, such as composite-aluminum-titanium structures, in aerospace industry.
This paper presents the smart cutting tools which act as the essential interface devices between smart machine tools and smart machining processes. The smart tooling can also be extended into smart fixtures and jigs, which are indispensable parts of smart machining systems particularly applicable in the context of Industry 4.0 and beyond [26].

Acknowledgements The authors gratefully acknowledge the committed support of all the technical staff of the AMEE Department at Brunel University London. Particular gratitude is expressed to Dr Saiful Anwar Bin Che Ghani, Dr Hui Ding and Mr Paul Yates.

Open Access This article is distributed under the terms of the Creative Commons Attribution 4.0 International License (http://crea tivecommons.org/licenses/by/4.0/), which permits unrestricted use, distribution, and reproduction in any medium, provided you give appropriate credit to the original author(s) and the source, provide a link to the Creative Commons license, and indicate if changes were made.

\section{References}

1. J B Hentz, V K Nguyen, W Maeder, et al. An enabling digital foundation towards smart machining. 8th CIRP Conference on Intelligent Computation in Manufacturing Engineering, 2013, 12: 240-245.

2. G W Vogl, M A Donmez, A Archenti. Diagnostics for geometric performance of machine tool linear axes. CIRP Annals - Manufacturing Technology, 2016, 65(1): 377-380.

3. B Peukert, S Benecke, J Clavell, et al. Addressing sustainability and flexibility in manufacturing via smart modular machine tool frames to support sustainable value creation. The 22nd CIRP Conference on Life Cycle Engineering, 2015, 29: 514-519.

4. M Fujishima, M Mori, K Nishimura, et al. Study on quality improvement of machine tools. The 5th International Conference on Through-life Engineering Services (TESConf 2016), 2017, 59: 156-159.

5. C Prinz, F Morlock, S Freith, et al. Learning factory modules for smart factories in Industrie 4.0. 6th CIRP Conference on Learning Factories, 2016, 54: 113-118.

6. K Cheng, D H Huo. Micro Cutting: Fundamentals and Applications. John Wiley \& Sons Ltd, Chichester, October 2013.

7. J Tlusty, G Andrews. A critical review of sensors for unmanned machining. Annals of the CIRP, 1983, 32 (2): 611-622.

8. M Weck. Machine diagnostics in automated production. Manuf. Syst, 1983, 2 (2): 101-106.

9. R Teti, K Jemielniak, G O'Donnell, et al. Advanced monitoring of machining operations. CIRP Annals - Manufacturing Technology, 2010, 59: 717-739.

10. K Cheng. Machining Dynamics: Theory, Applications and Practices. Springer, London, 2008.

11. J L Stein, K Huh. Monitoring cutting forces in turning: A model: Base approach. Manuf. Sci. Eng., Trans. ASME. 2002, 124: 27-31.

12. W Sawangsri, K Cheng. An innovative approach to cutting force modelling in diamond turning and its correlation analysis with tool wear. Proc. IMechE, Part B J. of Engineering Manufacture, 2016, 230(3): 405-415.

13. C Ferri, T Minton, K Cheng, et al. Internally cooled tools and cutting temperature in contamination-free machining. Proc. IMechE, Part C: J. of Mechanical Engineering Science, 2014, 228(1): 135-145. 
14. T Kim, J Kim. Adaptive cutting force control for a machining center by using indirect cutting force measurements. International Journal of Machine Tools \& Manufacture, 1995, 36: 925-937.

15. C Wang, R Rakowski, K Cheng. Design and analysis of a piezoelectric film embedded smart cutting tool. Proc. IMechE, Part B: J. Engineering Manufacture, 2013, 227: 254-260.

16. P Alfred. A review of wireless SAW sensors. IEEE Transactions on Ultrasonics, Ferroelectrics, and Frequency Control, 2000, 47: 317-322.

17. H Moussa, C Andrew, W Wojtek. Acoustic wave sensors: design, sensing mechanisms and applications. Smart Mater. Struct, 1997, 6: 647-657.

18. M Hofer. Finite-element simulation of wave propagation in periodic piezoelectric SAW structures. IEEE Transactions on Ultrasonics, Ferroelectrics, and Frequency Control, 2006, 53: 1192-1201.

19. B Donohoe, D Geraghty, G E O'Donnell. Wireless calibration of a surface acoustic wave resonator as a strain sensor. IEEE Sensors Journal, 2011, 11: 1026-1032.

20. E M Trent, P K Wright. Metal cutting. 4th ed. ButterworthHeinemann, Woburn Massachusetts, July 2000.

21. A Saiful. Design and analysis of the internally cooled smart cutting tools with the applications to adaptive machining. PhD Thesis, Brunel University, 2013.

22. X Sun, R Bateman, K Cheng, et al. Design and analysis of an internally cooled smart cutting tool for dry cutting. Proc. IMechE, Part B: J. Engineering Manufacture, 2011, 226: 585-591.

23. $\mathrm{H} \mathrm{Li}, \mathrm{R}$ Ibrahim, K Cheng. Design of an innovative compliant fast tool servo for precision engineering. Mech. Sci, 2011, 2: 139-146.

24. D H Huo, K Cheng. A dynamics-driven approach to the design of precision machine tools for micro-manufacturing and its implementation perspectives. Proc. IMechE, Part B: J. Engineering Manufacture, 2008, 222: 1-13.

25. C Wang, K Cheng, R Rawkoski. Cutting force based analysis and correlative observations on the tool wear in diamond turning of single-crystal silicon. IMechE, Part B: J. Engineering Manufacture, 2015, 229(10): 1867-1873.
26. K Cheng. Keynote presentation - 2: Smart tooling, smart machines and smart manufacturing: Working towards the Industry 4.0 and beyond. IEEE International Conference on Automation and Computing (ICAC2015), Glasgow, UK, September 2015.

Kai Cheng, born in December 1961, is currently a Chair Professor and Theme Leader in Ultraprecision and Micro/Nano Manufacturing at Brunel University London, United Kingdom. Professor Cheng is a Fellow of the IMechE and IET since 2004. His current research interests include ultraprecision and micro machining, design of smart tooling and smart machining, multiscale multi-physics based design and analysis, and sustainable manufacturing systems. Tel: +44 (0)1895-267255; E-mail: kai.cheng@brunel.ac.uk.

Zhi-Chao Niu, born in September 1990, is currently a PhD candidate in Ultraprecision and Micro/Nano Manufacturing Theme at Brunel University London, United Kingdom. He received his master degree on Advanced Engineering Design from Brunel University London. His research interests include ultraprecision and micro machining, micro cutting mechanics, and composite materials machining. Tel: +44(0)7743844131; E-mail: zhichao.niu@brunel.ac.uk.

Robin C. Wang, is currently a research fellow at Brunel University London, United Kingdom. His current research interests include smart cutting tools, design of air-bearings, and smart machining. E-mail: chao.wang@brunel.ac.uk.

Richard Rakowski, is currently a senior lecturer at Brunel University London, United Kingdom. His current research focuses on smart cutting tools, manufacturing metrology, and creative engineering design. E-mail: richard.rakowski@brunel.ac.uk.

Richard Bateman, is currently a lecturer at Brunel University London, United Kingdom. His main research interests include energysmart manufacturing, digital and e-manufacturing. E-mail: richard.bateman@coventry.ac.uk. 